\title{
Personality Analysis Through Handwriting
}

\author{
Rashi Kacker and Hima Bindu Maringanti, \\ Department of Computer Engineering, JIIT, Noida \\ rashi.kacker86@gmail.com, hima.bindu@jiit.ac.in
}

\begin{abstract}
This work discusses about computer aided Graphology i.e. Personality analysis based on handwritten text, in which instead of a Graphologist, a system will be trained to perform the analysis without much human intervention. A real world dataset of handwritten text samples will be maintained and based on few features like Margins, Baseline, Size, Zones etc. depicted in each of the samples and extracted through Image processing techniques and, an approximate analysis of the writer's personality trait will be done. These traits will then be mapped to the existing personality theories and finally a personality type, temperament and a detailed report will be given for the handwritten sample, as the result of analysis.
\end{abstract}

Index Terms - Graphology, Personality Traits, Handwritten Text, Feature Extraction, Margins, Baselines, Zones.

\section{INTRODUCTION}

$\mathrm{G}$ RAPHOLOGY is the pseudoscientific study and analysis of handwriting. Handwriting is a physical process with an expressive and silent gesture; the brain sends an instruction through the nervous system to the arm, hand and fingers which together manipulate the writing tool. Beyond the conscious information contained in the written words, the handwriting also divulges information about the writer's unconscious feeling (and psychological state to some extent). Each individual's handwriting is the projections of his/her personality, smallest of features depict particular traits of the writer's way of thinking and also about his/her general life style. Graphology's applications include Employment profiling, Business compatibility, Psychological analysis, marital compatibility, Medical diagnosis, Jury screening, Grapho-therapy, Forensic document examination and various others [1][2][3][4][5].Munsterberg [6] wrote way- back in 1913 that "Certain correlations exist between the neatness, carefulness, uniformity, energy, and similar features of the letter, and the general carefulness, steadiness, neatness, and energy of the personality". Over 2000 years back, the Greek philosopher Aristotle [7] noticed the correlation between handwriting and personality. [8] Carl Jung proposed the psychological concepts related to an individual's personality, based on those theories Myer Briggs [9] proposed a type indicator for diverse personalities based on the four dichotomies as shown in the Table I.

\begin{tabular}{|c|}
\hline Dichotomies \\
\hline Extraversion (E) - (I) Introversion \\
\hline Sensing (S) - (N) Intuition \\
\hline Thinking (T) - (F) Feeling \\
\hline Judgment (J) - (P) Perception \\
\hline
\end{tabular}

These four dichotomies serve as the basis of the Keirsey's Temperament Sorter, Briggs four dichotomies form sixteen personality types and each of these are associated with a temperament through Keirsey's temperament sorter as shown in the Table II.

\begin{tabular}{|c|c|c|c|}
\hline $\begin{array}{c}\text { ISTJ } \\
\text { ( Inspector) }\end{array}$ & $\begin{array}{c}\text { ISFJ } \\
\text { ( Protector) }\end{array}$ & $\begin{array}{c}\text { INFJ } \\
\text { ( Counselor) }\end{array}$ & $\begin{array}{c}\text { INTJ } \\
\text { ( Mastermind) }\end{array}$ \\
\hline $\begin{array}{c}\text { ISTP } \\
\text { ( Crafter) }\end{array}$ & $\begin{array}{c}\text { ISFP } \\
\text { ( Composer) }\end{array}$ & $\begin{array}{c}\text { INFP } \\
\text { ( Healer) }\end{array}$ & $\begin{array}{c}\text { INTP } \\
\text { (Architect) }\end{array}$ \\
\hline $\begin{array}{c}\text { ESTP } \\
\text { ( Promoter) }\end{array}$ & $\begin{array}{c}\text { ESFP } \\
\text { ( Performer) }\end{array}$ & $\begin{array}{c}\text { ENFP } \\
\text { ( Champion) }\end{array}$ & $\begin{array}{c}\text { ENTP } \\
\text { ( Inventor) }\end{array}$ \\
\hline $\begin{array}{c}\text { ESTJ } \\
\text { ( Supervisor) }\end{array}$ & $\begin{array}{c}\text { ESFJ } \\
\text { ( Provider) }\end{array}$ & $\begin{array}{c}\text { ENFJ } \\
\text { ( Teacher) }\end{array}$ & $\begin{array}{c}\text { ENTJ } \\
\text { ( Field Marshal) }\end{array}$ \\
\hline
\end{tabular}

The handwriting is full of varied styles depending upon individuals these are also called features, the different features considered for this work are margins, slants, size, baselines, spacing between lines and words, the ratio of zones and degree of connection between the letters. The present work addresses calculation of these features and mapping them to the Briggs types and through that dichotomy, to the Keirsey's temperament sorter so as to give a detailed report to the user about personality type and temperament he/she belongs to.

\section{BACKGROUND}

A survey [11] was carried out in order to document the current state of art, the proposals for research in handwriting analysis and Contemporary topics, actors and resources in graphonomics. The (Table III) summarizes the current scenarios of computer aided handwriting analysis. 
Table III. Summary of Surveys and projects in handwriting analysis.

\begin{tabular}{|l|l|l|}
\hline Field & Uses & $\begin{array}{l}\text { Handwriting } \\
\text { Characteristics }\end{array}$ \\
\hline Biometrics & $\begin{array}{l}\text { Verification of } \\
\text { identities, } \\
\text { authentication of } \\
\text { financial } \\
\text { transactions } \\
\text { based on } \\
\text { signature } \\
\text { verification, } \\
\text { monitoring of } \\
\text { health }\end{array}$ & $\begin{array}{l}\text { Dynamic aspects of } \\
\text { handwriting: sequence of } \\
\text { character construction, } \\
\text { duration of stroke length, } \\
\text { speed and acceleration } \\
\text { patterns of pen-tip } \\
\text { movement, pressure by } \\
\text { fingers on the writing } \\
\text { instrument and by the } \\
\text { instrument on the writing } \\
\text { surface. }\end{array}$ \\
\hline Forensic & $\begin{array}{l}\text { Police } \\
\text { investigations, } \\
\text { by security } \\
\text { agencies and } \\
\text { detectives by } \\
\text { lawyers in court } \\
\text { as evidence } \\
\text { material. }\end{array}$ & $\begin{array}{l}\text { Layered transparencies } \\
\text { for visual comparison of } \\
\text { handwriting, computer } \\
\text { aided search of letter } \\
\text { shape prototypes in an } \\
\text { online database. }\end{array}$ \\
\hline $\begin{array}{l}\text { Reading one's } \\
\text { psychology from } \\
\text { the person's } \\
\text { handwriting. }\end{array}$ & $\begin{array}{l}\text { Dating } \\
\text { localization and } \\
\text { writing or } \\
\text { tradition } \\
\text { identification } \\
\text { and the inference } \\
\text { of socio cultural } \\
\text { aspects based on } \\
\text { the analysis of } \\
\text { handwriting. }\end{array}$ & $\begin{array}{l}\text { Laselines, slants, size, } \\
\text { spacing etc[10]. } \\
\text { the convex hull bounding } \\
\text { the characters, tangent } \\
\text { distance and statistical } \\
\text { analysis to classify Latin } \\
\text { letters. }\end{array}$ \\
\hline Graphology \\
\hline
\end{tabular}

\section{A. Literature}

The literature for the personality analysis through handwriting includes, analysis based on baselines and slants using a combined crisp and fuzzy approach [12], analysis generated through artificial neural networks based on the pen pressure variations in writings, the positioning of the ' $t$ ' bars and the baselines [13]. Another system trained a SVM to predict the behaviour of the writer based on slant of letters and words, baseline, pen pressure, spacing between letters, and words [14].Another method was proposed for behavioural prediction of a person through automated handwriting analysis, it identified the psychological traits namely baseline, number of breaks, margins, speed of writing, and spacing between the words, this analysis was done with the help of image processing in MATLAB [15].

\section{FOCUS OF WORK}

This work focuses on the better and detailed analysis report of an individual's personality based on psychological traits depicted in the offline handwritten text. The detailed report includes a personality type based on Myer Briggs dichotomies, a temperament based on Kersey's temperament sorter, and a detailed data related to portrait of the personality and the personal growth of that personality type.

\section{A. Data Collection}

The real time data is collected for the analysis around 50 samples are collected and analyzed, these data samples are written on an A4 sized plain white sheet, in black ink. The content is required to be directly from the thought process of the writer it should not be copied or dictated and should not include any type of lists.

\section{B. Architecture}

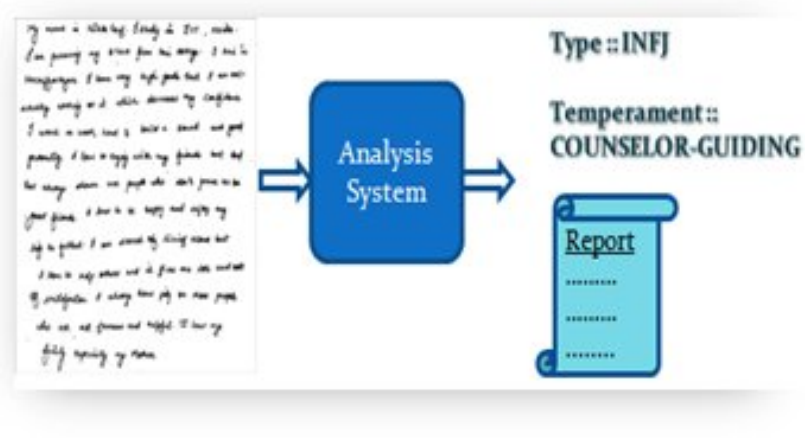

Fig 1. The proposed system

\section{IMPLEMENTATION AND RESULTS}

This work focuses on the better and detailed analysis report of an individual's personality based on psychological traits depicted in the offline handwritten text. The detailed report includes a personality type based on Myer Briggs dichotomies, a temperament based on Kersey's temperament sorter, and a detailed data related to portrait of the personality and the personal growth of that personality type.

\section{A. Algorithm}

The analysis system follows the following steps

Step 1: Scan the samples.

Step 2: Threshold the samples.

Step 3: Binarize the image.

Step 4: Apply the thinning algorithm [16]

Step 5: Perform Segmentation.

Step 6: Extract the features.

Step 7: Analyse.

Step 8: Map with Briggs dichotomies.

Step 9: Display the results.

The features extracted in this work are margins, size, slant, degree of connection between the letters, spacing between lines and ratio of the three zones in handwriting namely the upper, middle and lower zone.

\section{B. Margins and Baselines}

Margins and baselines are calculated using the following equation

$$
\theta=\tan ^{-1}(l / d)
$$


Where ' $l$ ' is the length of the written content and ' $d$ ' is the distance of the first black pixel of first line from 0 for ' $\theta$ ', and distance of the first black pixel of the last line from 0 for ' $\theta_{1}$ ', similarly for the baseline ' $\alpha$ ' and ' $\alpha_{1}$ ' are calculated.

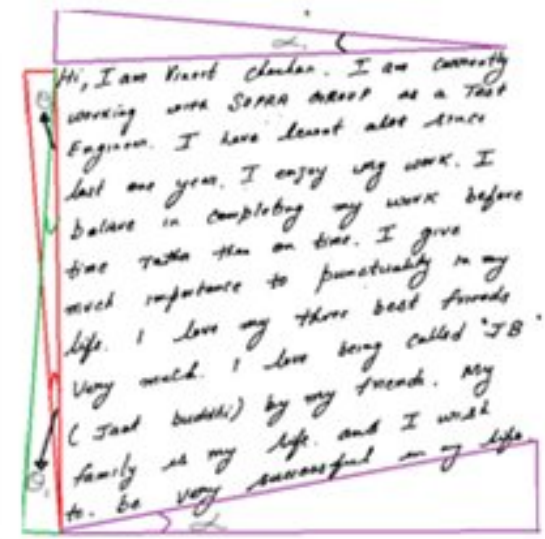

Fig 2:The margins and baseline.

\section{Size}

The size of the letters is calculated by taking the average sizes of the middle zone threshold letters. Normal handwriting has a benchmark of $3 \mathrm{~mm}$ and full height of $9 \mathrm{~mm}$. Other than this, writing is classified as small or large writing.

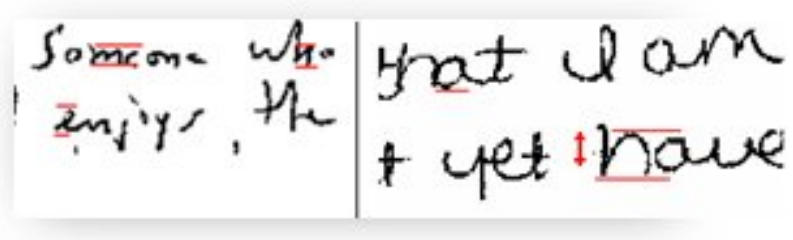

Fig 3:Size.

\section{Slants and Zones}

The slants and zone ratios of the writing have a standard notation as shown in figure 4 and 5 . The slants are calculated with respect to the baseline; the slope of each letter is calculated and then averaged to get the degree of slant. If the ratios of the three zones are calculated with respect to each other and if it is a balanced zone, then all the three will be almost equal, if not then the dominant one is stored for reference.

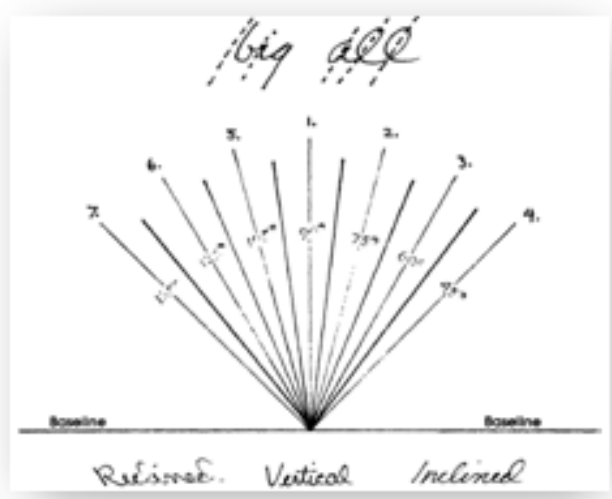

Fig 4: The Slants [10]

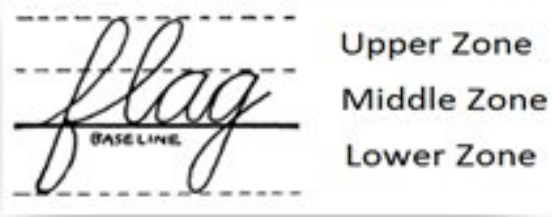

Fig 5: Zones [10]

\section{E. Spacing}

For the spacing in between the lines, the numbers of consecutive white pixels in a given range are calculated; the range is decided after the segmentation of lines.

\section{F. Degree of Connection}

The degree of connection in between the letters is calculated by counting the white pixels in between a word and dividing it by the number of pixels in that word.

\section{G. Final Mapping}

These features are then mapped to the dichotomies, arrived at by us, in consultation with the domain expert. The mapping is as shown in Table IV.

Table IV: Mapping of traits.

\begin{tabular}{|c|c|}
\hline Dichotomies & Features \\
\hline$(\mathrm{E})-(\mathrm{I})$ & Size, Slant \\
\hline$(\mathrm{S})-(\mathrm{N})$ & Margins, Zonal ratio \\
\hline$(\mathrm{T})-(\mathrm{F})$ & Space, Slant \\
\hline$(\mathrm{J})-(\mathrm{P})$ & $\begin{array}{c}\text { Degree of connection, } \\
\text { Space }\end{array}$ \\
\hline
\end{tabular}


Thus, based on the respective features, four matrices for each of the dichotomies, mentioned in Table 4, are formed which are summed up to give out a personality type and temperament is evaluated from Table 2.If the user wishes, a detailed report with personality portrait and prediction of personal growth trends, is displayed to the user, by linking this result to an existing dataset.

\section{CONCLUSION}

This work focuses on the mapping of features to the two famous personality theories, Briggs and Keirsey's to give a detailed report without the manual flaws that could occur in the multiple choice based personality analysis systems. In multiple choice questions, the user might not be able to decide which is the exact trait-resembling option, which in turn might cause incorrect analysis. This work includes limited physical features of handwriting. Extension of this work may include more features like different types of strokes, thickness of characters and pen pressure variation etc. Natural Language Processing may also be augmented to the present work, wherein the semantics of words used by the writer, would provide the analyzer with additional perspective.

\section{ACKNOWLEDGMENT}

Our sincere thanks due to, Mr. Bhupesh Dhundele a world renowned graphologist, who took time from his busy schedule to provide us with a deeper insight to this enormous and fascinating field of Graphology.

\section{REFERENCES}

[1] M.Simner, W.Hulstijn and P.Giouard, (1994)"Forensic, Developmental and Neuropsychological Aspects of Handwriting", special issue, I. Forensic Document

[2] M.L.Simner, C.G.Leedham and A.J.W.M.Thomassen, eds., (1996) "Handwriting and Drawing Research: Basic and Applied Issues." 10s Press, 1996.

[3] Acta Psychologica, G. P.Van Galen and P. Morasso,(1998) "Neuromotor Control in handwriting and Drawing,", eds., vol. 100, nos. 1-2, p. 236, 1998..125

[4] G. P. Van Galen and G. E. Stelmach,(1993) "Handwriting: Issues of Psychomotor Control and Cognitive Models," Acta Pychologica, eds., special volume, Amsterdam North Holland.

J. Wan, A. M. Wing and N. Sovik,(1991)

"Development of Graphic Skills: Research, Perspectives and Educational Implications." eds., London: Academic Press.

[6] Bradley N (2005)" Users of Graphology", Graphology, the Journal of the British Academy of Graphology. (January) 69 pp55-57.

[7] http://en.wikipedia.org/wiki/Aristotle

[8] http://en.wikipedia.org/wiki/Carl_Jung

[9] http://en.wikipedia.org/wiki/Myers-Briggs_Type_Indicator

[10] Karen Amend and Mary S. Ruiz, (1980)" Handwriting Analysis The Complete Basic Book",
New Page Books.

[11] Vlad Atanasiu,(2004) "Research conducted for the benefit of the Commission for Scientific Visualization", Austrian Academy of Sciences, Tech Gate Vienna.

[12] Mogharreban, N.; Rahimi, Shahram; and Sabharwal, M., (2004) "A Combined Crisp and Fuzzy Approach for Handwriting Analysis", Publications. Paper 27.

[13] Champa H N,Dr. K R AnandaKumar,(2010) "Artificial Neural Network for Human Behaviour Prediction through handwriting Analysis", International Journal of Computer Applications (0975 - 8887) Volume 2 - No.2, May 2010.

[14] Shitala Prasad, Vivek Kumar Singh, Akshay Sapre,(2010) "Handwriting Analysis based on Segmentation Method for Prediction of Human Personality using Support Vector Machine",

International Journal of Computer Applications (0975 - 8887) Volume 8-No.12, October 2010

[15] Vikram Kamath, Nikhil Ramaswamy, P. Navin Karanth, Vijay Desai and S. M. Kulkarni, (2011) "Development of an Automated Handwriting Analysis System", ARPN Journal of Engineering and Applied Sciences Volume 6- No.9, September 2011 ISSN 1819-660.

[16] G.S. Ng, R.W Zhou and C. Quek, (1994) "A Novel Single pass Thinning Algorithm “,

Submitted to IEEE Transaction on Systems, Man and Cybernetics September 1994. 